Supplement of Hydrol. Earth Syst. Sci., 22, 567-580, 2018

https://doi.org/10.5194/hess-22-567-2018-supplement

(c) Author(s) 2018. This work is distributed under

the Creative Commons Attribution 4.0 License.

(c) (1)

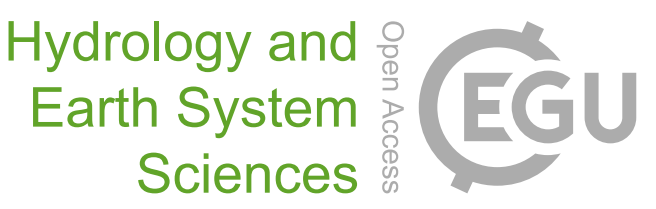

Supplement of

\title{
Dominant effect of increasing forest biomass on evapotranspiration: interpretations of movement in Budyko space
}

Fernando Jaramillo et al.

Correspondence to: Fernando Jaramillo (fernando.jaramillo@natgeo.su.se)

The copyright of individual parts of the supplement might differ from the CC BY 4.0 License. 

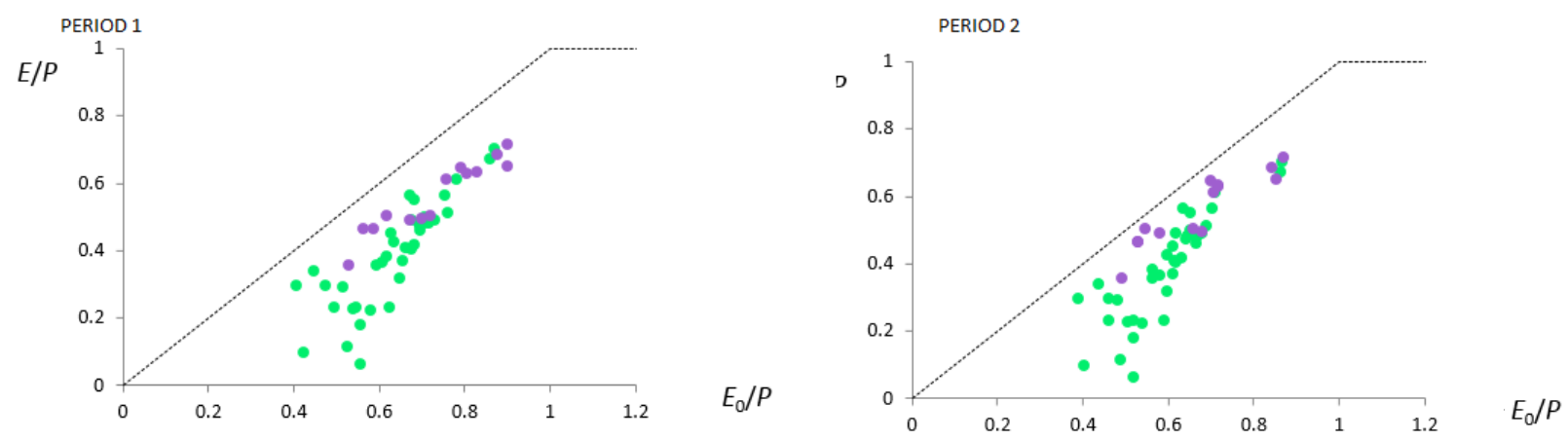

Figure S1- Mean hydroclimatic conditions of the 60 basins illustrated in Budyko space, in terms of the aridity index $\left(E_{0} / P\right.$; x-axis) and evaporative ratio $(E / P ; \mathrm{y}$-axis) for temperate (purple) and boreal (green) basins during the periods (a) 1961-1986 and (b) 1987-2012.

Table S1- Statistical parameters of the linear regressions between the residual of the evaporative ratio, $(E / P)_{\mathrm{r}}$, and the forest attributes of forest biomass $(V)$, forest cover $(A)$, forest composition $\left(Q_{\mathrm{v}}\right)$ and fraction of precipitation falling as snow $\left(f_{\mathrm{s}}\right)$ in the boreal and temperate basin groups. Results are shown for the regressions using annual $(N=52)$, three-year $(N=17)$ and five-year means $(N=10)$ during the period 1961-2012. Significant p-values are shown in bold font and shaded in grey, while nearly significant pvalues $(0.05<\mathrm{p}<0.10)$ shown in red font.

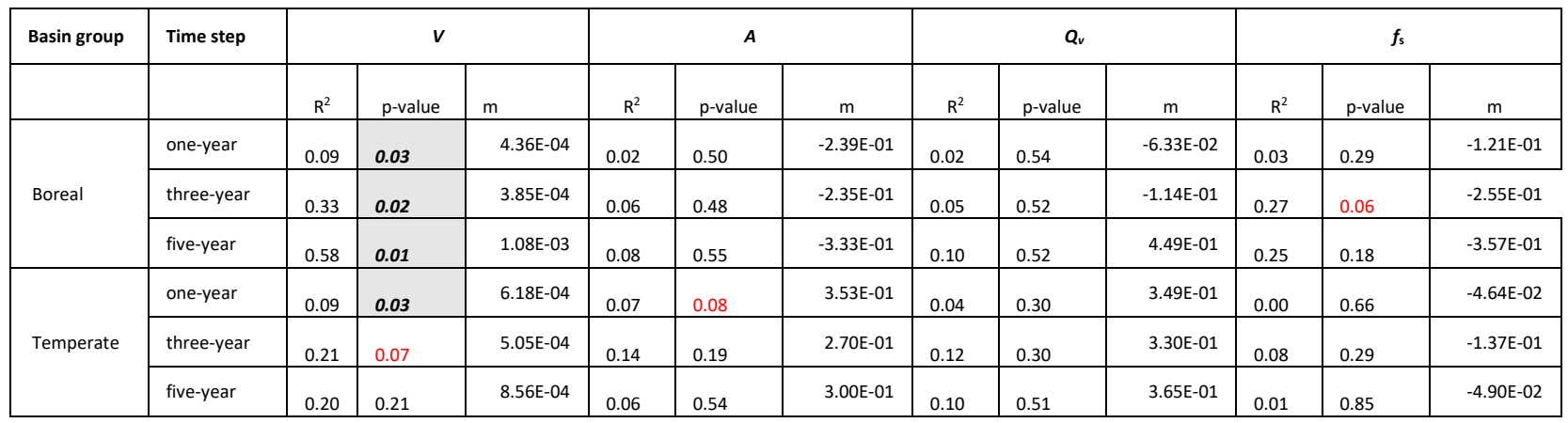

